\title{
Proper depiction of monsoon depression through IRS-P4 MSMR
}

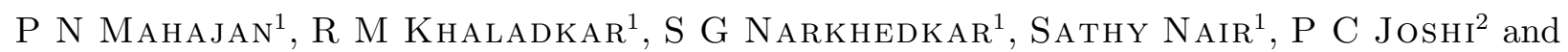 \\ $\mathrm{P} \mathrm{K} \mathrm{PAL}{ }^{2}$ \\ ${ }^{1}$ Indian Institute of Tropical Meteorology, Pune 411 008, India. \\ ${ }^{2}$ Space Applications Center, Ahmedabad 380 015, India.
}

In this paper, daily variations of satellite-derived geophysical parameters such as integrated water vapour (IWV), cloud liquid water content (CLW), sea surface temperature (SST) and sea surface wind speed (SSW) have been studied for a case of monsoon depression that formed over the Bay of Bengal during 19th-24th August 2000. For this purpose, IRS P4 MSMR satellite data have been utilized over the domain equator $-25^{\circ} \mathrm{N}$ and $40^{\circ}-100^{\circ} \mathrm{E}$. An integrated approach of satellite data obtained from IRS-P4, METEOSAT-5 and INSAT was made for getting a signal for the development of monsoon depression over the Indian region. Variations in deep convective activity obtained through visible, infrared and OLR data at 06 UTC was thoroughly analyzed for the complete life cycle of monsoon depression. Geophysical parameters obtained through IRS-P4 satellite data were compared with vorticity, convergence and divergence at 850 and $200 \mathrm{hPa}$ levels generated through cloud motion vectors (CMVs) and water vapour wind vectors (WVWVs) obtained from METEOSAT-5 satellite. This comparison was made for finding proper consistency of geophysical parameters with dynamical aspects of major convective activity of the depression.

From the results of this study it is revealed that there was strengthening of sea surface winds to the south of low-pressure area prior to the formation of depression. This indicated the possibility of increase in cyclonic vorticity in the lower troposphere. Hence, wind field at $850 \mathrm{hPa}$ with satellite input of CMVs in objective analysis of wind field using optimum interpolation (OI) scheme was computed. Maximum cyclonic vorticity field at $850 \mathrm{hPa}$ was obtained in the region of depression just one day before its formation. Similarly, with the same procedure maximum anticyclonic vorticity was observed at $200 \mathrm{hPa}$ with WVWVs input. Consistent convergence and divergence at 850 and $200 \mathrm{hPa}$ was noticed with respect to these vorticities. In association with these developments, we could get lowest values of OLR $\left(120 \mathrm{~W} / \mathrm{m}^{2}\right)$ associated with major convective activity that was consistent with the maximum values of integrated water vapour $\left(6-8 \mathrm{gm} / \mathrm{cm}^{2}\right)$ and cloud liquid water content $\left(50-60 \mathrm{mg} / \mathrm{cm}^{2}\right)$ persisting particularly in the southwest sector of the monsoon depression.

\section{Introduction}

Important weather systems such as depressions generally developing in a quasi-stationary planetary scale monsoon trough over the Bay of Bengal and entering the east coast of India before proceeding further in westerly/northwesterly direc- tion and giving widespread rainfall over the different parts of central India are recognized as the most important synoptic situations during southwest monsoon season. It is noticed from the observations of many years of meteorological data that on an average the life period of monsoon depression is about 3-5 days. It is also seen that

Keywords. Monsoon depression; IRS P4 MSMR; OLR.

Proc. Indian Acad. Sci. (Earth Planet. Sci.), 113, No. 2, June 2004, pp. 223-233

(C) Printed in India. 
the number of depressions varies from year to year. These depressions seldom acquire very strong intensity presumably due to large vertical wind shear and short travel over the seas. Nevertheless, they have high probability of intensification during September when the vertical wind shear weakens.

Due to high potential in producing widespread rainfall, the monsoon depressions have attracted the attention of various forecasters for a long time. Eliot (1884) had noted that these events were regular features of southwest monsoon season over the Indian region. During more than four decades, a number of researchers both in India and abroad have tried to look into various aspects of monsoon depressions (Srinivasan 1953, Pisharoty and Asnani 1957, Rao and Jayaraman 1958, Bhalme 1972, Mooley 1973; Sikka 1977; Sarkar and Chowdhury 1988 etc). Irrespective of numerous studies undertaken on monsoon depressions the present knowledge acquired on this matter is still inadequate and sketchy. A clear understanding of variations in geophysical parameters for the complete life cycle of monsoon depression is yet to emerge in detail. This is due to lack of observational data over oceans.

For a better understanding of large-scale structural features of monsoon depressions, it is necessary to utilize our IRS-P4 satellite data to apprehend more clearly its diagnostic and prognostic potentialities. Geophysical parameters such as SST, SSW, IWV and CLW are computed using suitable algorithms (Gohil et al 2000). These geophysical parameters are validated and accuracies are determined (Ali et al 2000). Accuracies for SST, SSW, IWV and CLW are of the order of $1.2^{\circ} \mathrm{K}, 2 \mathrm{~ms}^{-1}, 0.25 \mathrm{gm} / \mathrm{cm}^{2}$ and $10 \mathrm{mg} / \mathrm{cm}^{2}$ respectively. These parameters are further compared with other satellite data obtained from DMSP and NOAA satellites of USA and found to agree well, except CLW (Varma et al 2002). Uses of DMSP-SSM/I derived geophysical parameters (SSW, IWV) are highlighted by Mahajan (2001, 2002a) for diagnostic study of monsoon depression formed during July 1992. The MSMR data are also assimilated in NCMRWF model for assessing impact (Kamineni et al 2002). IRS-P4 MSMR data have been used for all the cases of monsoon depressions formed over the Indian region from 1999 to 2001. In this paper, complete life cycle of monsoon depression from a stage of low to the dissipation of depression for the period 19th-24th August 2000 is highlighted in detail using geophysical parameters obtained through IRS-P4 MSMR, CMVs and WVWVs obtained through METEOSAT5 and visible and infrared imageries obtained through INSAT satellites over the Indian region.
Characteristic features associated with the complete life cycle of this depression have been brought out.

\section{Data}

IRS-P4 MSMR measurement at four frequencies viz., $6.6,10.65,18$ and $21 \mathrm{GHz}$ in dual polarization was used for monitoring areal coverage of monsoon depression during 19th-24th August 2000. MSMR grid data for sea surface temperature, sea surface wind speed, integrated water vapour and cloud liquid water content was utilized for monitoring the variability of geophysical parameters. INSAT and METEOSAT-5 visible and infrared imageries were used for analyzing the progress of development of convective activity over the region of monsoon depression. Figure 1 shows locations of monsoon depression and figure 2 depicts day-to-day variations in visible imageries at 06 UTC taken by INSAT satellite for the complete life period of monsoon depression. Outgoing longwave radiation (OLR) data matching with descending node of IRS-P4 is further used for identifying major convective activity associated with depression. CMVs and WVWVs obtained from METEOSAT-5 satellite were used for computing dynamical changes in lower and upper troposphere especially at 850 and $200 \mathrm{hPa}$ for the complete life cycle of depression over the Bay of Bengal region.

\section{Methodology}

Geophysical parameters obtained from IRS-P4 were used to get daily composite pictures. These pictures were in different resolutions. In this study, higher resolutions were used to get better highlights of development processes. Area covered by monsoon depression has given more importance to acknowledge the changes observed in development/dissipation stages. METEOSAT-5 derived CMVs and WVWVs were used for monitoring the dynamical changes at different stages of monsoon depression. For this purpose, CMVs and WVWVs were compared with conventional winds reported by radiosonde observations of Minicoy and Port Blair island stations over the Arabian Sea and the Bay of Bengal. Linear regression equations between METEOSAT5-derived winds at $850 \mathrm{hPa}$ and radiosonde winds at $850 \mathrm{hPa}$ were developed. Similar procedure was applied for $200 \mathrm{hPa}$. Statistical relationship between conventional winds and satellite-derived winds at 850 and $200 \mathrm{hPa}$ (Mahajan 2002a) obtained for independent data set is as follows: 


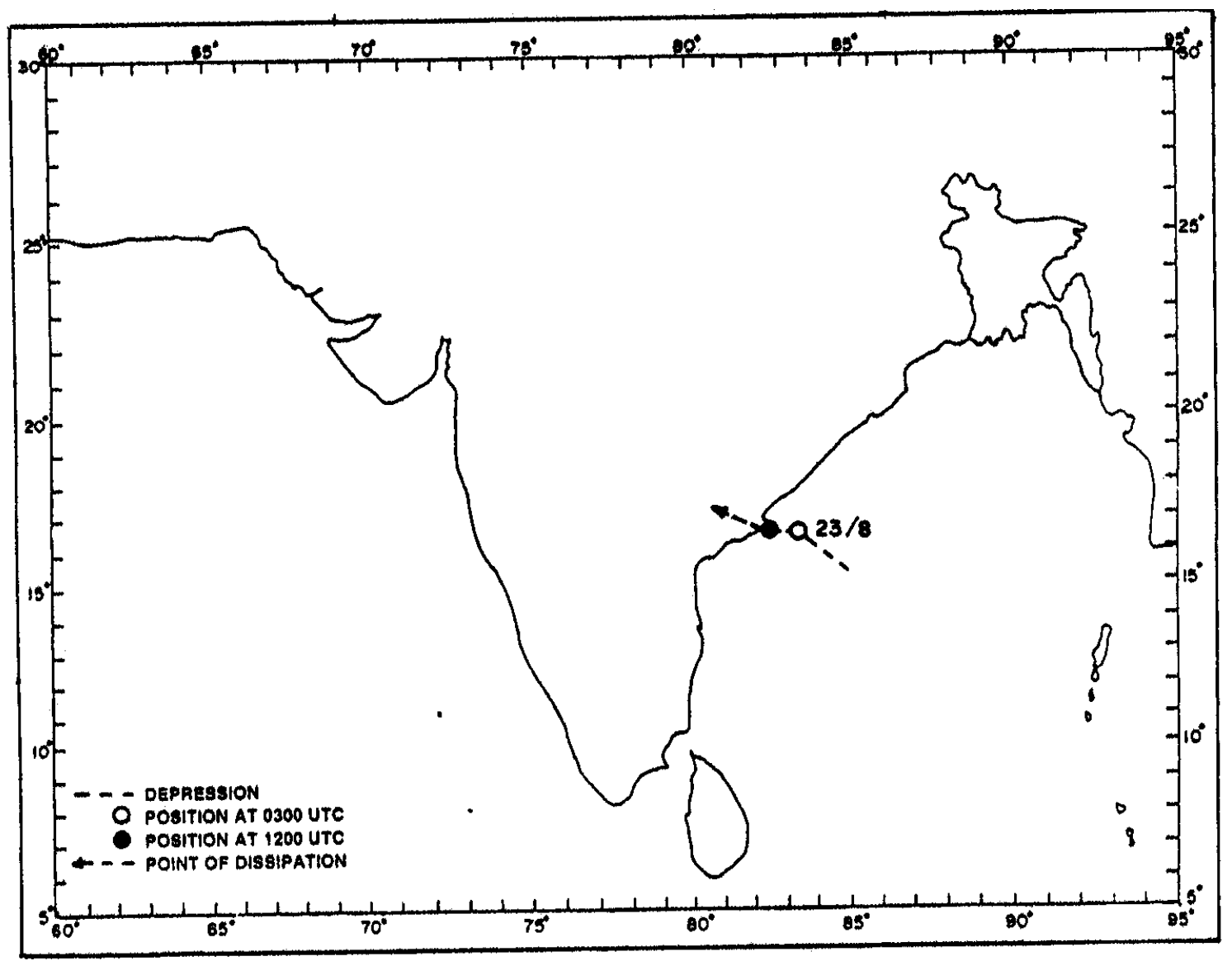

Figure 1. Track of monsoon depression, August 2000.

\begin{tabular}{ccccc}
\hline $\begin{array}{c}\text { Level } \\
(\mathrm{hPa})\end{array}$ & $\mathrm{n}$ & $\begin{array}{c}\text { Regression } \\
\text { relation }\end{array}$ & $\mathrm{r}$ & $\mathrm{SD}$ \\
\hline 850 & 105 & $\mathrm{Yu}(850)=3.51+0.97 \mathrm{X} 1$ & 0.79 & 4.11 \\
850 & 105 & $\mathrm{Yv}(850)=-1.76+0.95 \mathrm{X} 2$ & 0.74 & 3.59 \\
200 & 160 & $\mathrm{Yu}(200)=-3.71+0.83 \mathrm{X} 3$ & 0.53 & 8.51 \\
200 & 160 & $\mathrm{Yv}(200)=1.23+0.76 \mathrm{X} 4$ & 0.48 & 7.62 \\
\hline
\end{tabular}

Where $u(850)$ and $v(850)$ are estimated winds for $u$ and $v$ components at $850 \mathrm{hPa} . u(200)$ and $v$ (200) are estimated winds for $u$ and $v$ components at $200 \mathrm{hPa}$. $\mathrm{X} 1$ and $\mathrm{X} 2$ are $u$ and $v$ components of CMVs at $850 \mathrm{hPa}$ respectively. $\mathrm{X} 3$ and $\mathrm{X} 4$ are $u$ and $v$ components of WVWVs at $200 \mathrm{hPa}$. The above regression equations were used to modify the wind fields of METEOSAT-5 during the life period of the monsoon depression. National Centre for Environmental Prediction (NCEP) daily wind field analysis during life period of monsoon depression i.e., 19th-24th August 2000 was used for performing objective analysis (OI) of the wind field at 850 and $200 \mathrm{hPa}$ by including non- conventional winds obtained from METEOSAT-5. These satellite-derived winds at 850 and $200 \mathrm{hPa}$ were modified by regression equations. These modified winds were used in objective analysis of the wind field for the complete life period of monsoon depression over the Bay of Bengal. Later, using these objectively analysed wind fields, vorticity fields at 850 and $200 \mathrm{hPa}$ were computed. Special emphasis was given to monitor the vorticity fields in the region of monsoon depression activity. It was then compared with the cloudiness pattern and OLR field. MSMR derived daily geophysical parameters were compared with the intense convective activity in the area of depression. 
19 August 2000

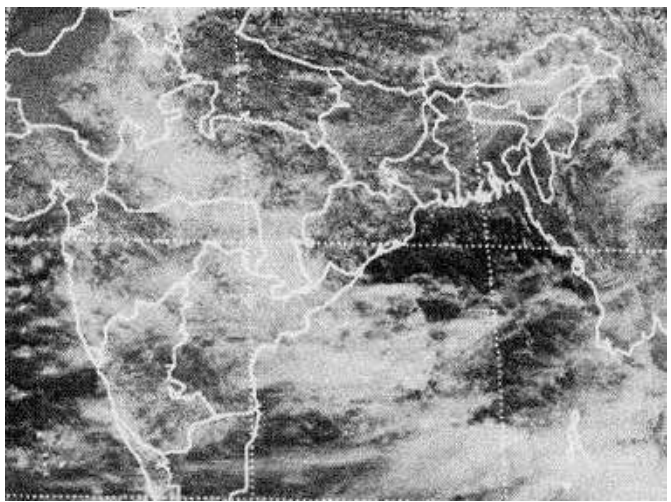

21 August 2000

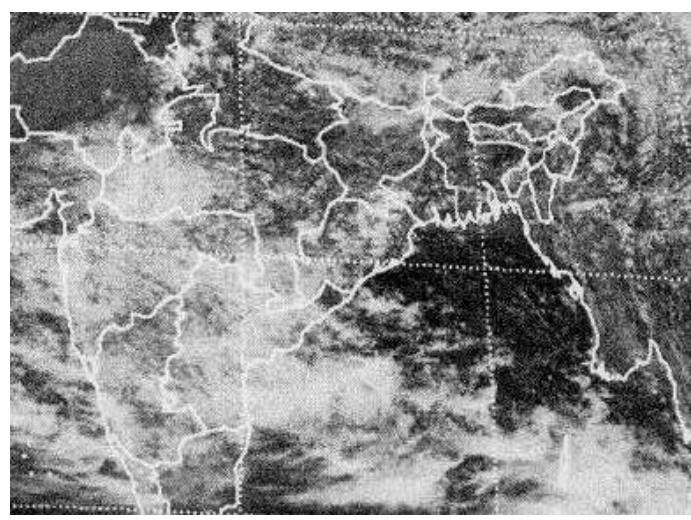

23 August 2000

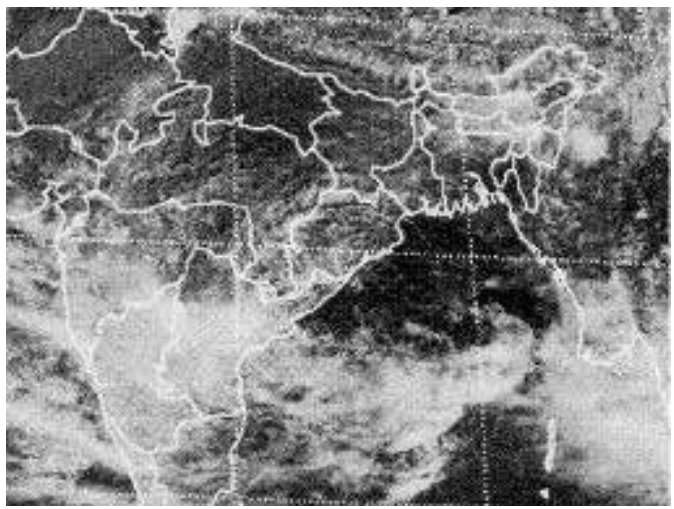

20 August 2000

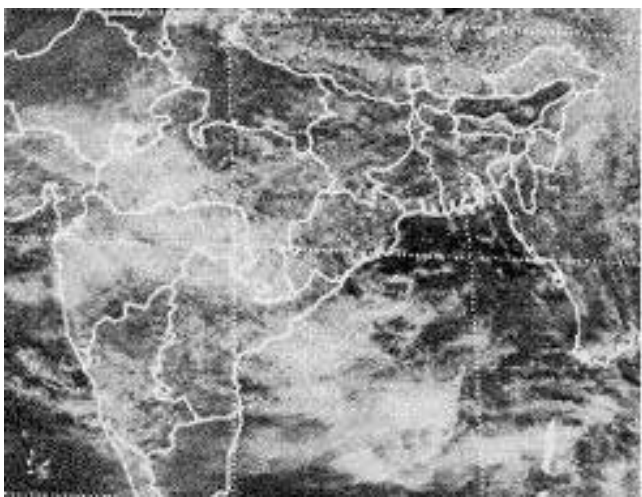

22 August 2000

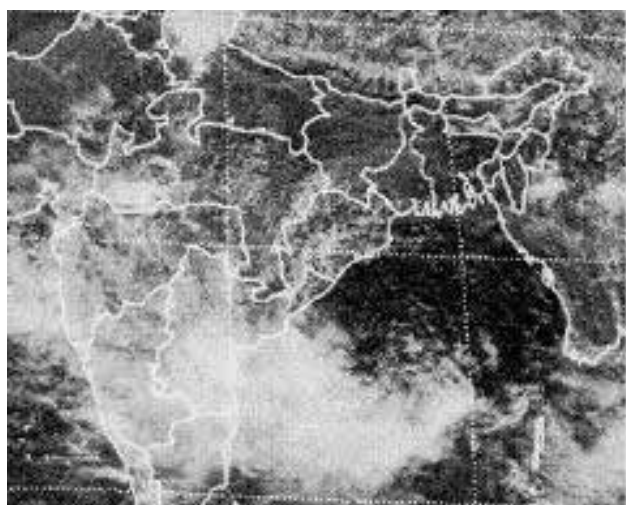

24 August 2000

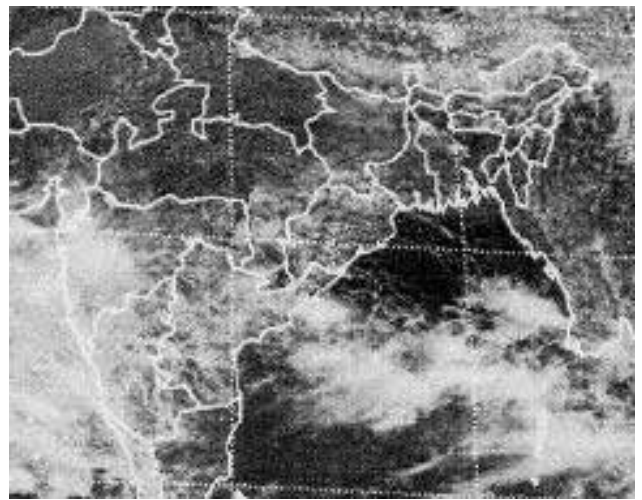

Figure 2. INSAT-1D imagery for monsoon depression.

\section{Results and discussion}

The following are the major results of the study:

- Sea surface temperature decreased by $2^{\circ} \mathrm{C}$ at some distance from the center of the depression. Particularly, this feature was observed from descending and ascending nodes of the satellite on 23rd August 2000.

- Sea surface wind speed to the south of low pressure area increased gradually from 12 to $16 \mathrm{mps}$ during 19th to 22nd August and it was maximum just one day before the formation of depression (figure 3).

- Maximum integrated water vapour of the order of $7.0-7.5 \mathrm{gm} / \mathrm{cm}^{2}$ (figure 5) was observed in the region of monsoon depression during 21st to 24th August.

- Maximum value of cloud liquid water content $50-60 \mathrm{mg} / \mathrm{cm}^{2}$ (figure 6) was noticed in major convective regions of monsoon depression on 22nd August. 
19.08 .00

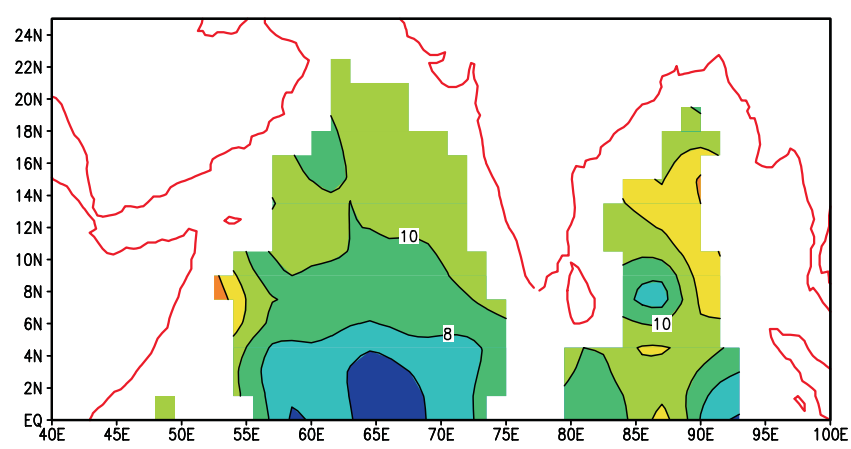

21.08 .00

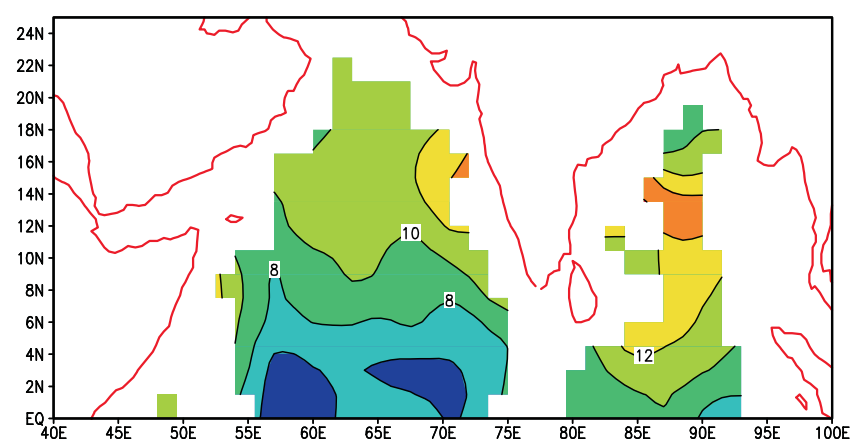

23.08 .00

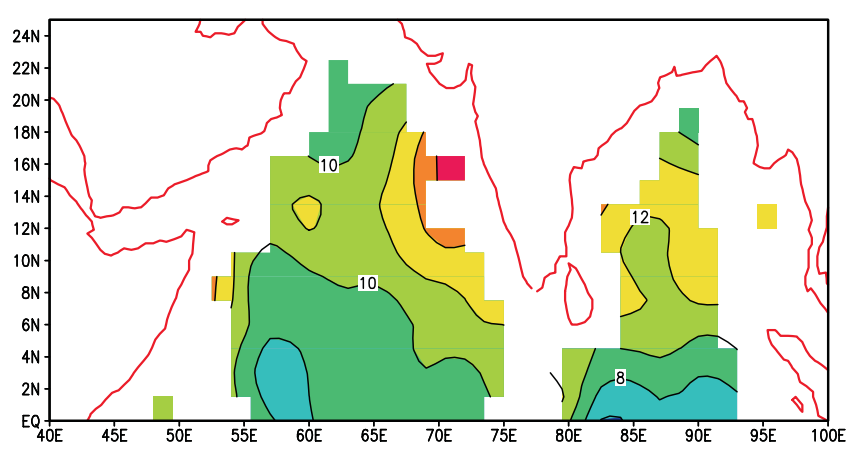

20.08 .00

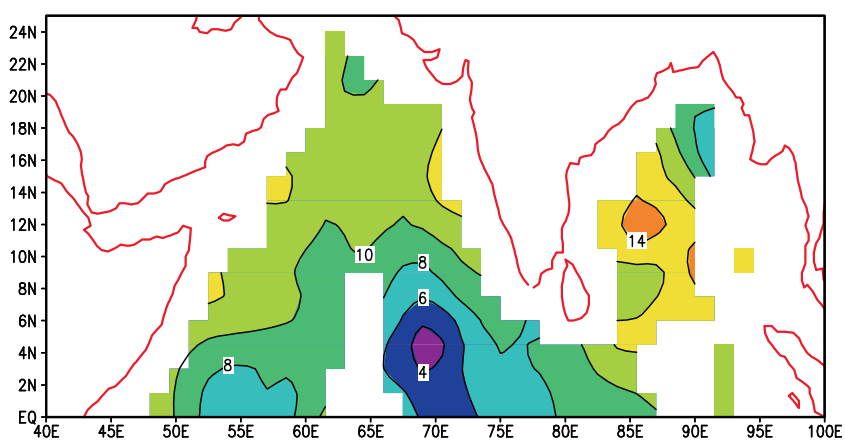

22.08 .00

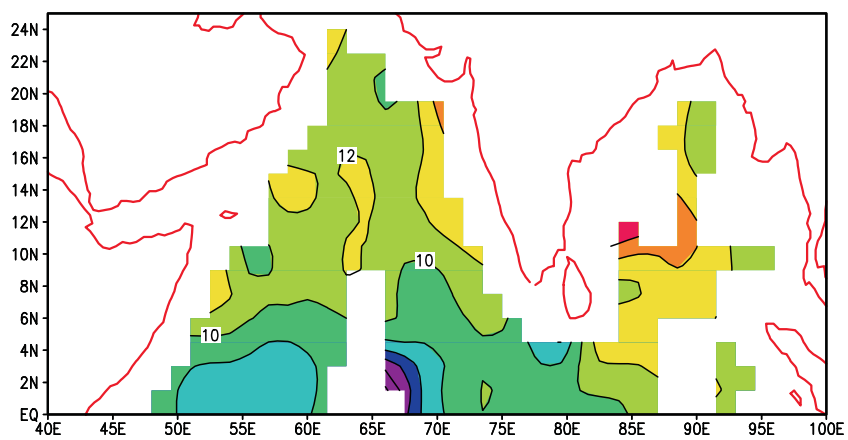

24.08 .00
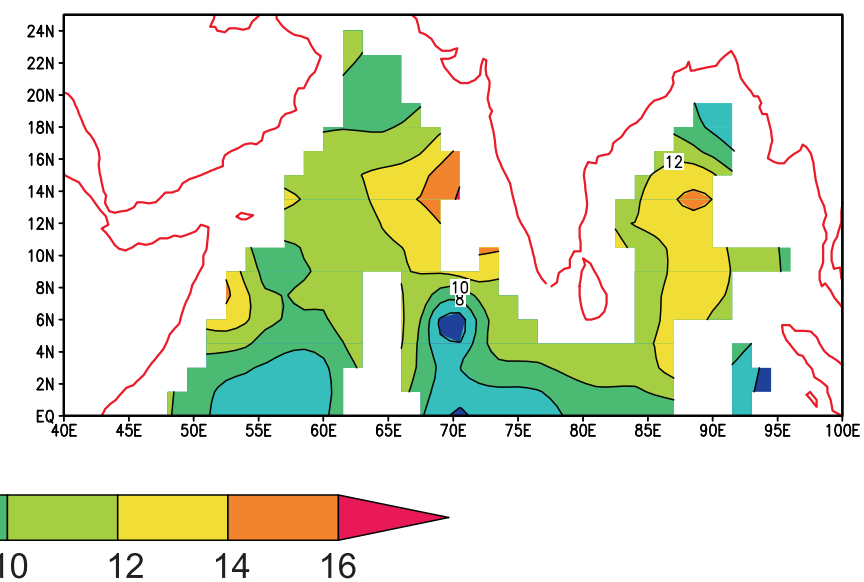

Figure 3. MSMR derived SSW (m/s) distribution during 19th-24th August 2000.

- Based on visible and infrared imageries of INSAT, METEOSAT-5 and OLR (INSAT) data at matching time (06 UTC) with descending node of IRS-P4, it was found that the existence of intense convective activity with low OLR values $\left(120 \mathrm{~W} / \mathrm{m}^{2}\right)$ was in the southwest sector of the monsoon depression.

- Maximum value of convergence $\left(-2.5 \times 10^{-5} / \mathrm{s}\right)$ at $850 \mathrm{hPa}$ (figure 7 ) and maximum value of divergence $\left(2.5 \times 10^{-5} / \mathrm{s}\right)$ at $200 \mathrm{hPa}$ (figure 8 ) were observed in the same region of low-pressure area on 22nd August, just one day before the formation of monsoon depression.

Sea surface temperature obtained from IRS-P4 data was varying from $29^{\circ}-32^{\circ} \mathrm{C}$ (figure 4 ) almost during the life period of monsoon depression. But sea surface temperature is found to decrease by $2{ }^{\circ} \mathrm{C}$ at the time of formation of the depression on 23rd August. This may be due to the churning 
19.08 .00

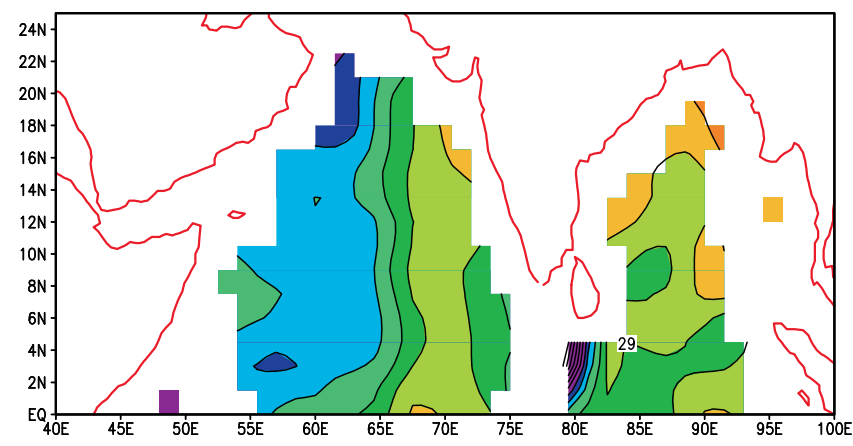

21.08 .00

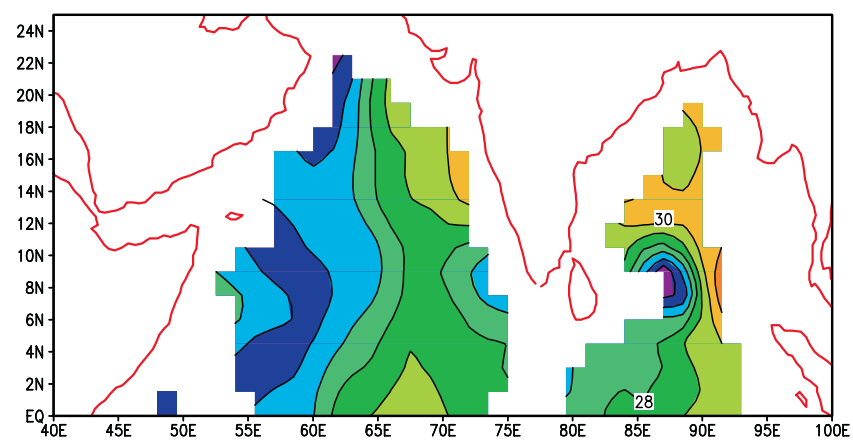

23.08 .00

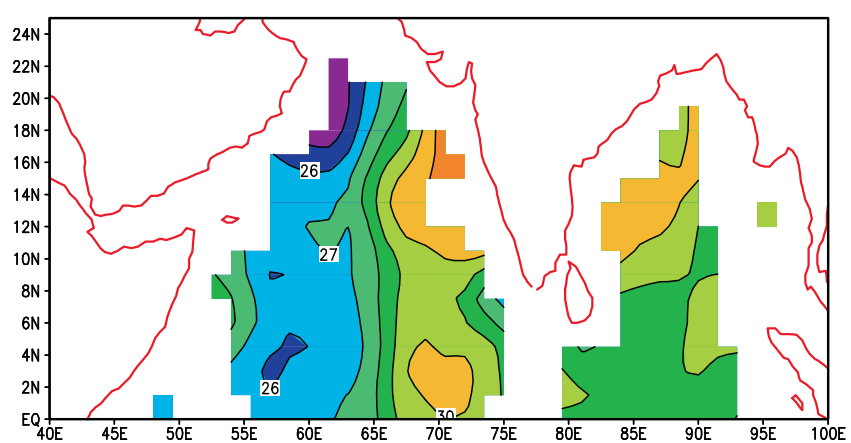

20.08 .00

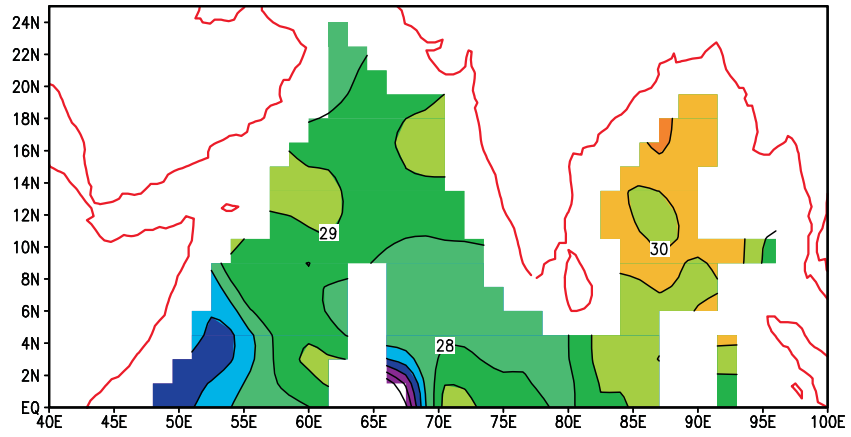

22.08 .00

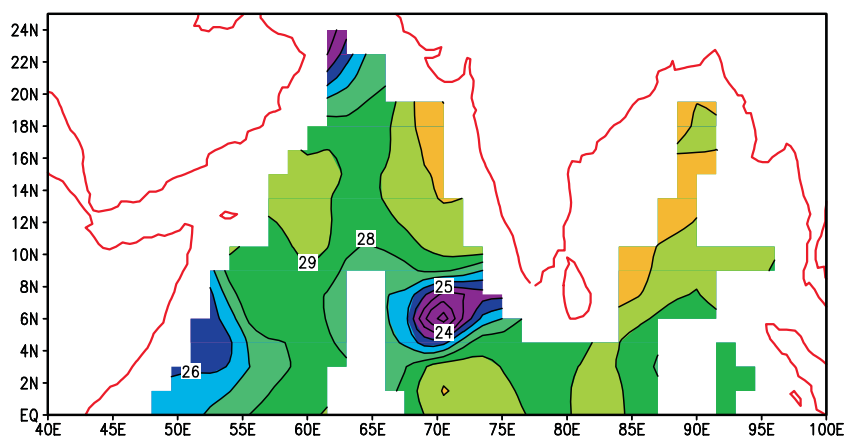

24.08 .00
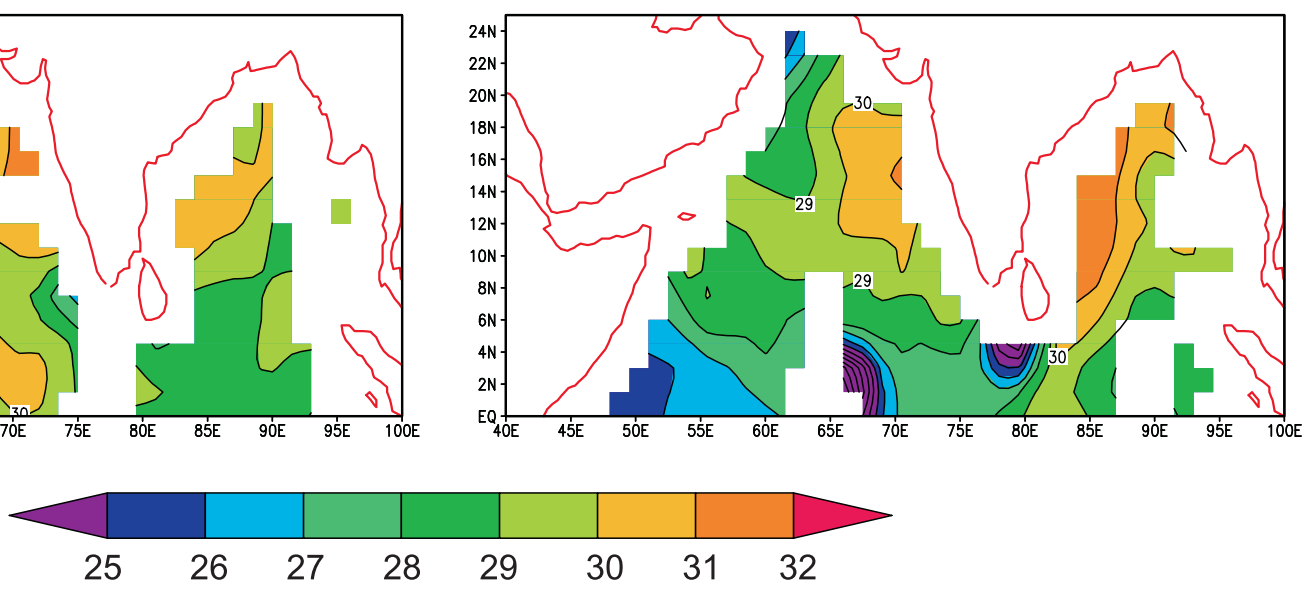

Figure 4. MSMR derived SST $\left({ }^{\circ} \mathrm{C}\right)$ distribution during 19th-24th August 2000.

and upwelling effect produced by sea surface winds during the development process. Sea surface wind speed started intensifying to the south of low pressure area giving an indication that cyclonic vorticity must have increased and that was a good indication for the development of low into depression. Considering this situation vorticity fields at $850 \mathrm{hPa}$ were computed for the whole life period of monsoon depression. This vorticity field was computed with input of CMVs in objective analysis of the wind field and it was noticed that the value of cyclonic vorticity was maximum just one day before the formation of depression. Similarly, vorticity field at $200 \mathrm{hPa}$ was computed with input of WVWVs in objective analysis of wind field and we noticed that similar characteristic features such as the value of anticyclonic vorticity was maximum, that too one day before the formation of depression. Thus, cyclonic vorticity and anticyclonic vorticity were maximum and matching at the 
19.08 .00

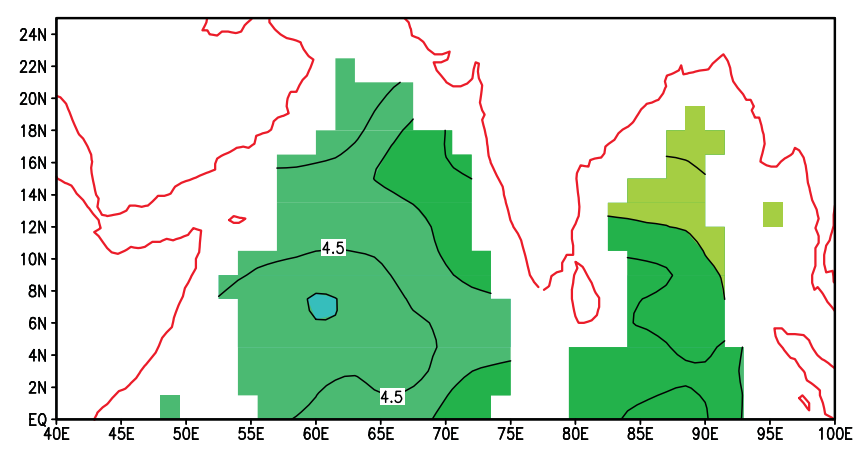

21.08 .00

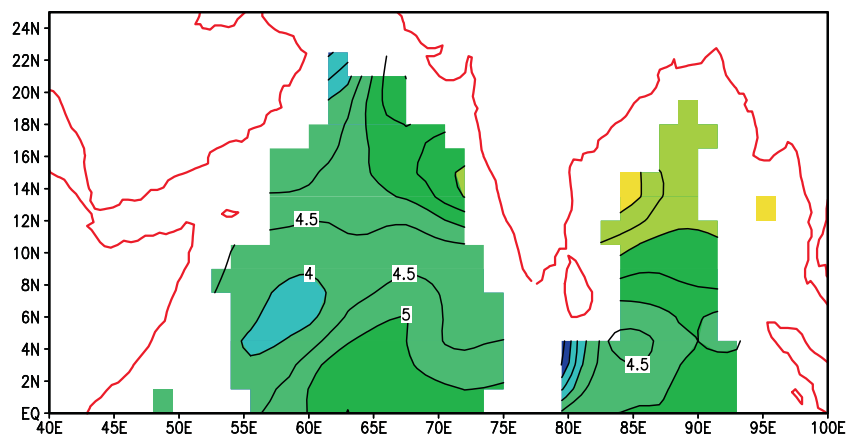

23.08 .00

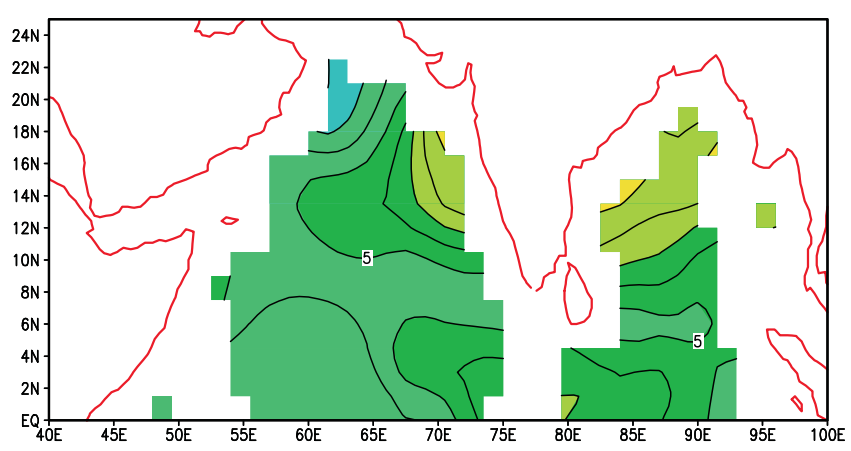

20.08 .00

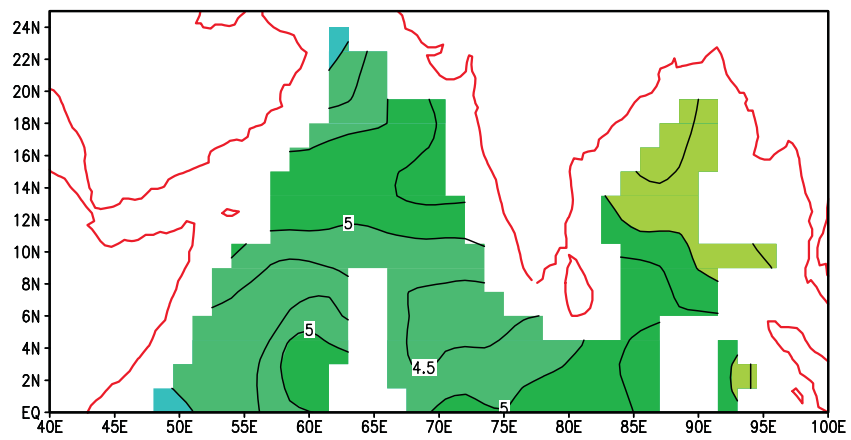

22.08 .00

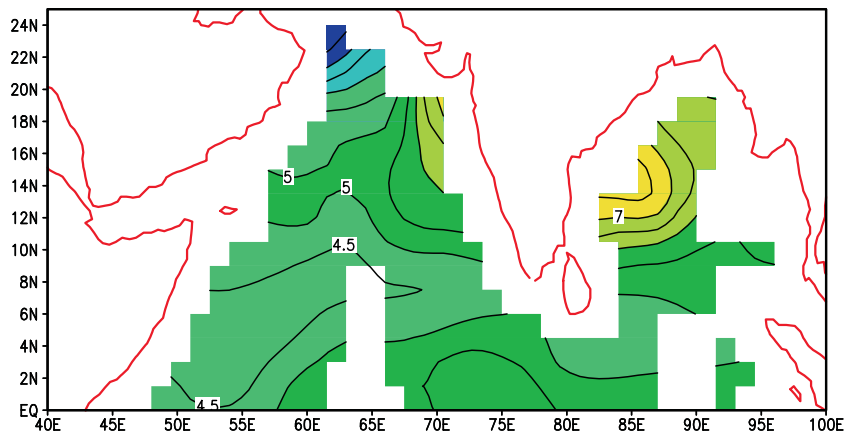

24.08 .00

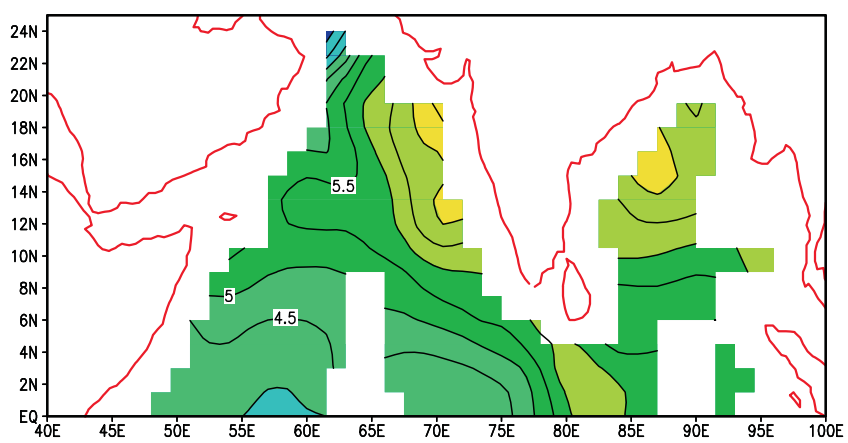

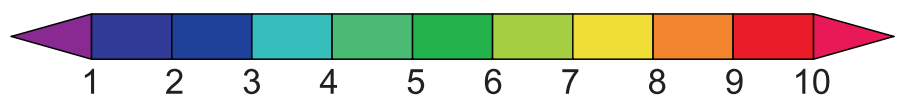

Figure 5. MSMR derived IWV $\left(\mathrm{gm} / \mathrm{cm}^{2}\right)$ distribution during 19th-24th August 2000.

location of formation of depression giving a signal for the development of depression. Accordingly, the depression was formed on 23rd August 2000. Low values of OLR $\left(120 \mathrm{~W} / \mathrm{m}^{2}\right)$ were noticed in the major convective region of the depression and it was mainly concentrated in the southwest sector of the depression. It is consistent with the results of the earlier researchers. On the same background the maximum values of integrated water vapour and cloud liquid water content were maximum in the region of major convective activity and it is appropriate as per the structural features of the depression. Cloud liquid water content values are not of expected accuracy as compared to other remote sensing satellites and NWP model estimates (Varma et al 2002). It is observed that cloud liquid water content values increase systematically from the day of formation of a low and are maximum just before the formation of depression. 
19.08 .00

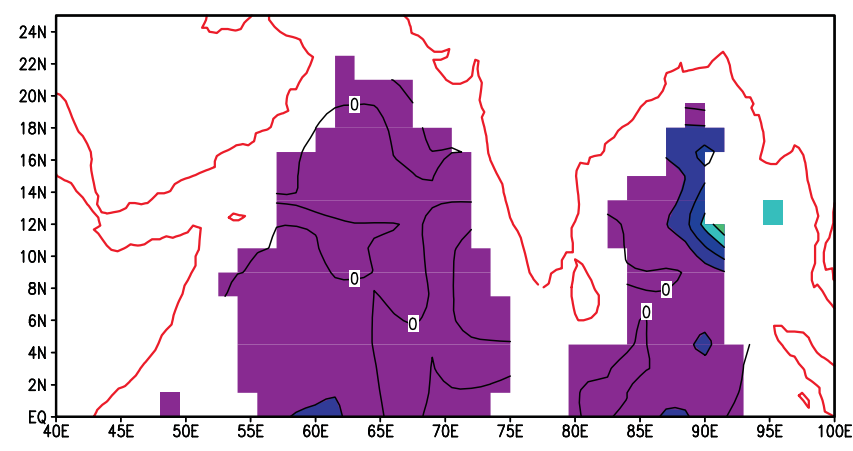

21.08 .00

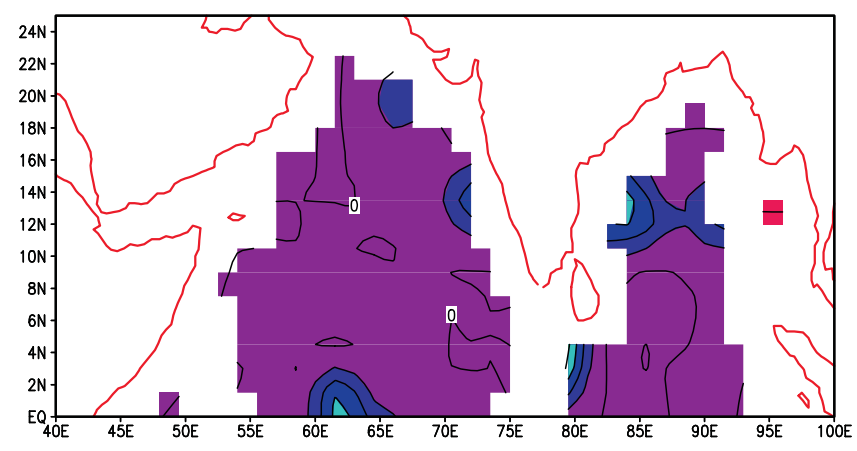

23.08 .00

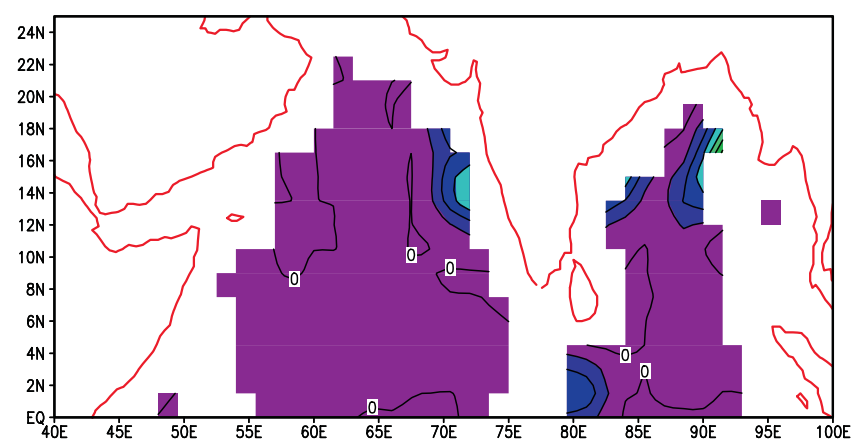

20.08 .00

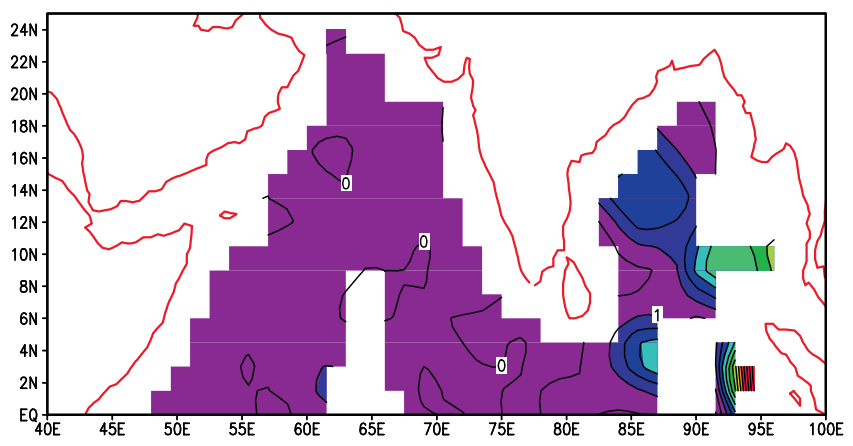

22.08 .00

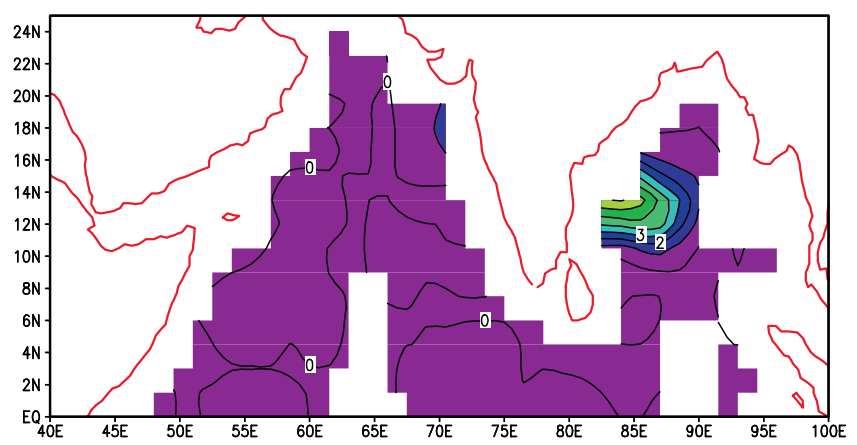

24.08 .00

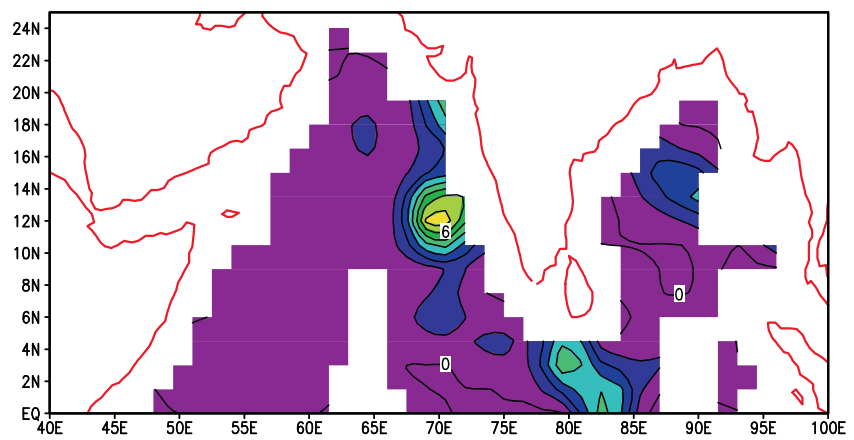

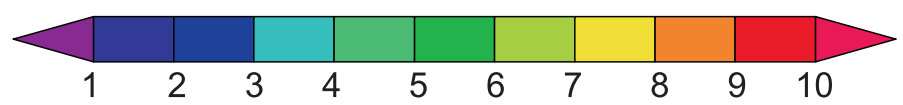

Figure 6. MSMR derived CLW (mg/ $\left.\mathrm{cm}^{2}\right)$ distribution during 19th-24th August 2000.

\section{Conclusion}

Depiction of proper variations in geophysical parameters through IRS-P4 MSMR and analysis of vorticity, convergence and divergence based on modified CMVs and WVWVs of METEOSAT-5 in objective analysis of the wind field at 850 and $200 \mathrm{hPa}$ gave a signal of development of monsoon depression over the Bay of Bengal during 19th-24th August 2000. It is suggested that this approach of utilizing multiple satellites will certainly help to improve the forecast of monsoon depressions over the Indian region.

\section{Acknowledgement}

This work was carried out under IITM-SAC collaborative program. The authors are grateful to Dr. G B Pant, Director, Indian Institute of Tropical 
19.08 .00

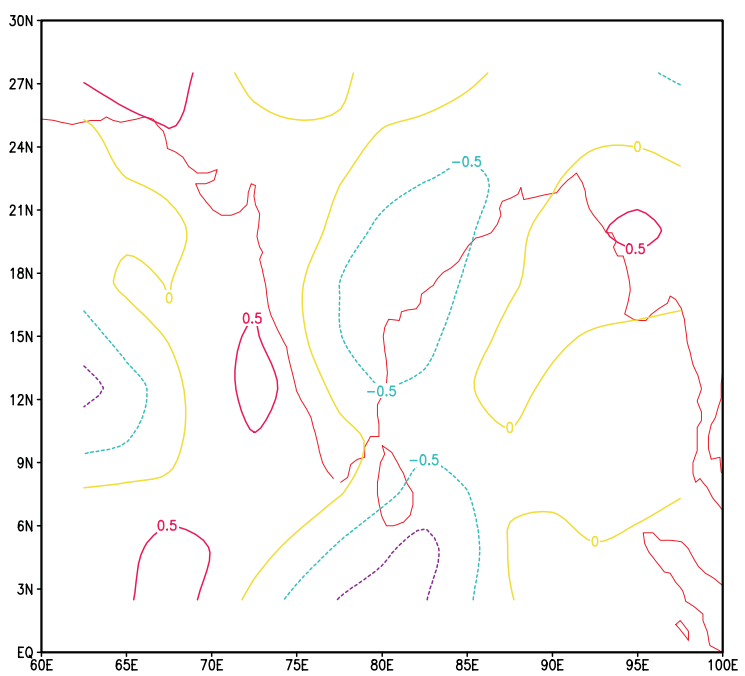

21.08 .00

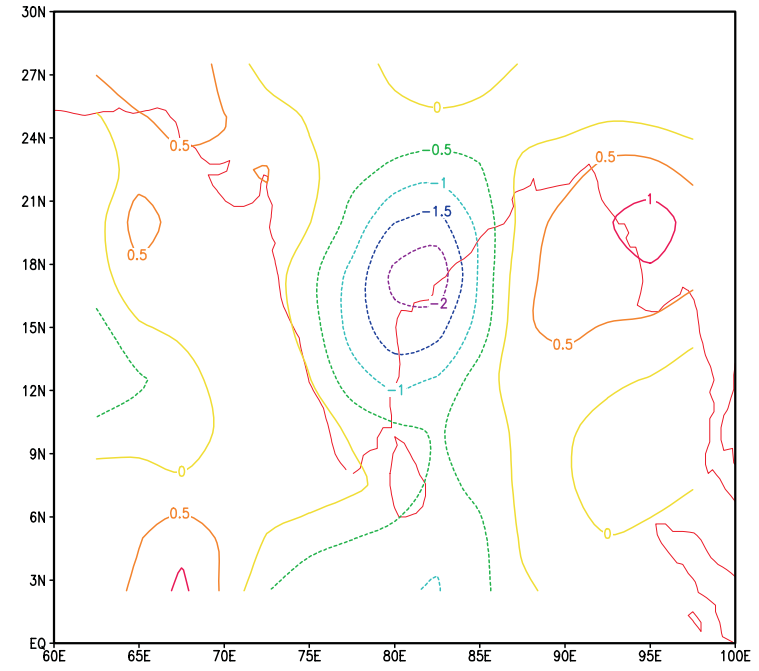

23.08 .00

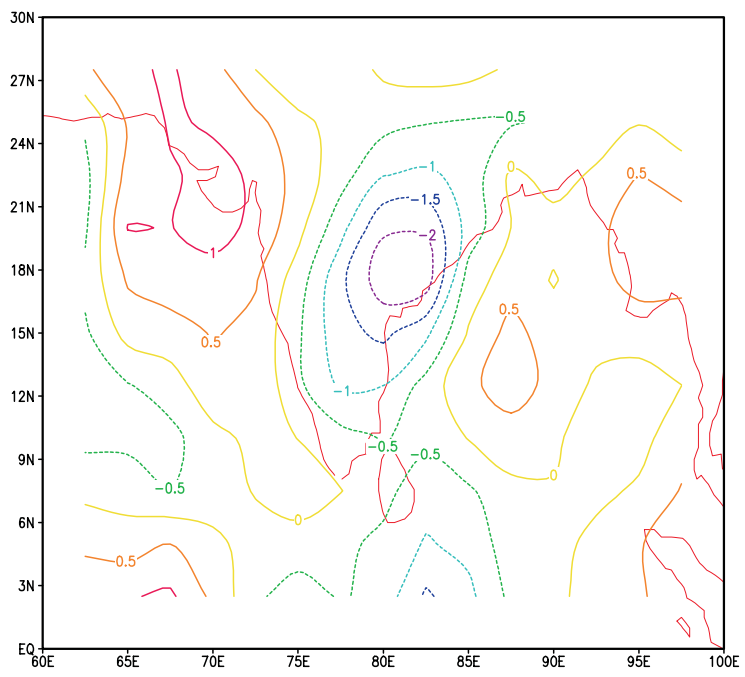

20.08 .00

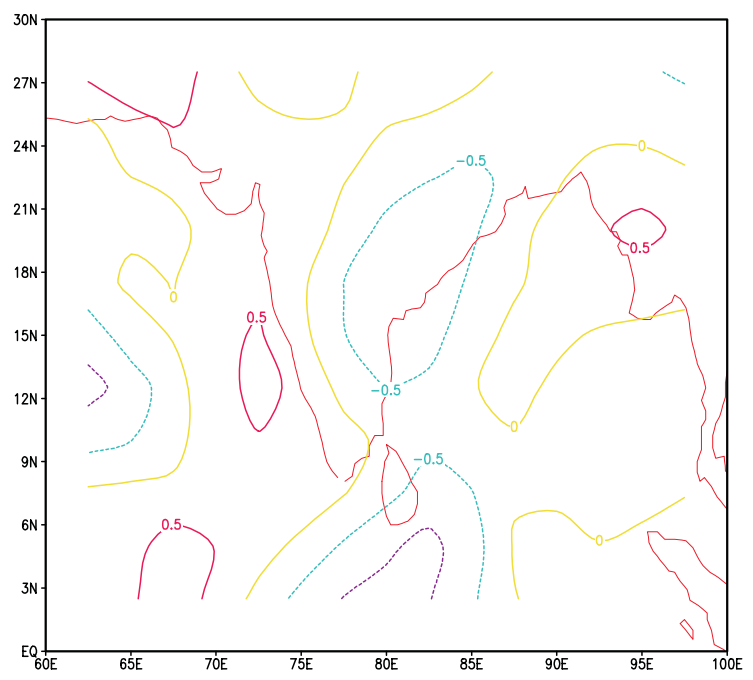

22.08 .00

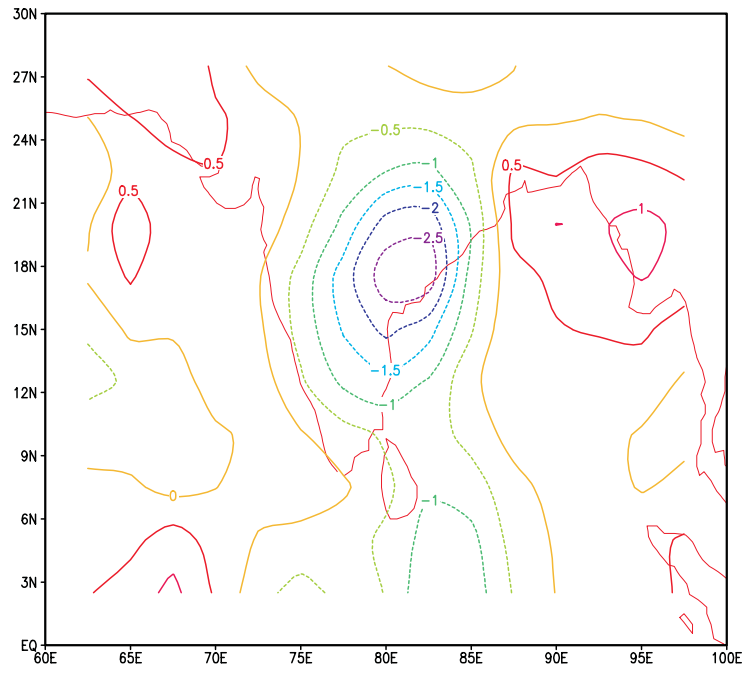

24.08 .00

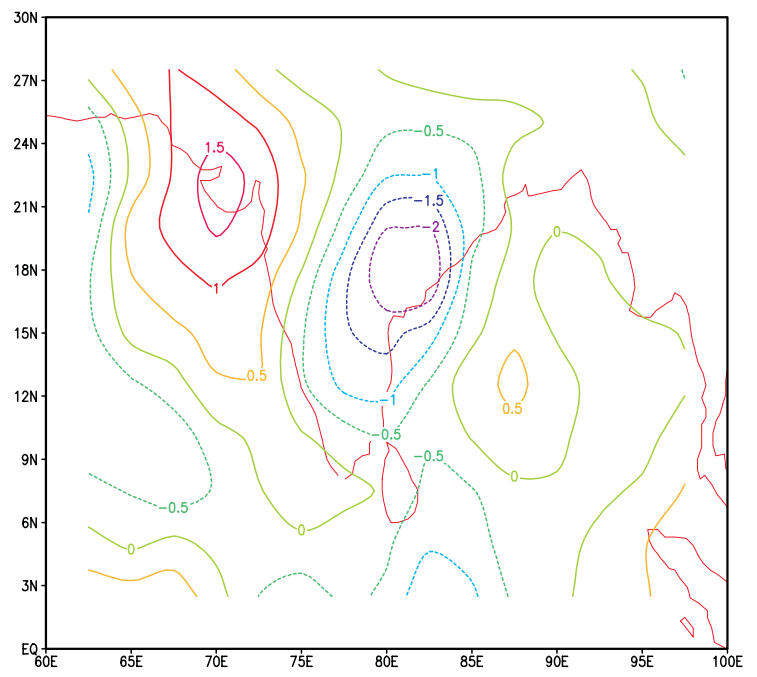

Figure 7. Divergence $\left(10^{-5} / \mathrm{s}\right)$ analysis at $850 \mathrm{hPa}$ for 19 th-24th August 2000. 
19.08 .00

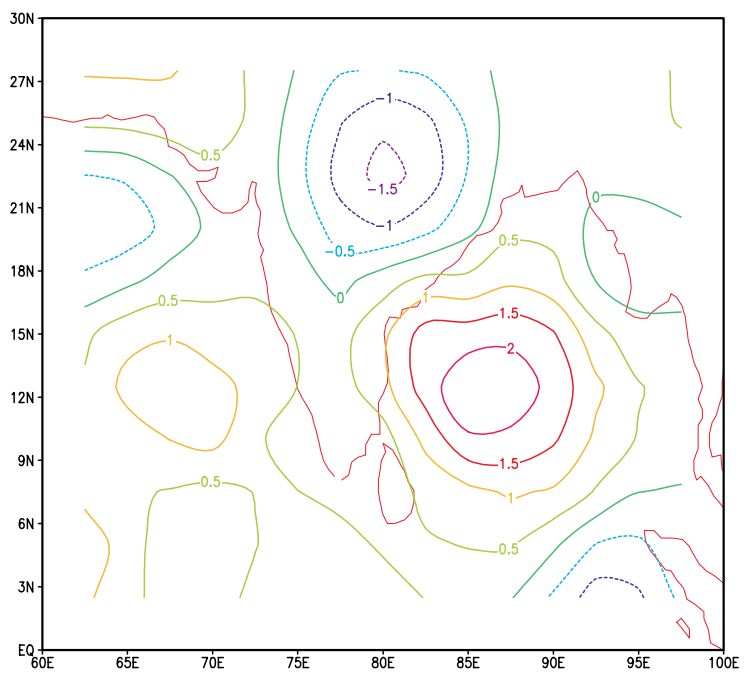

21.08 .00

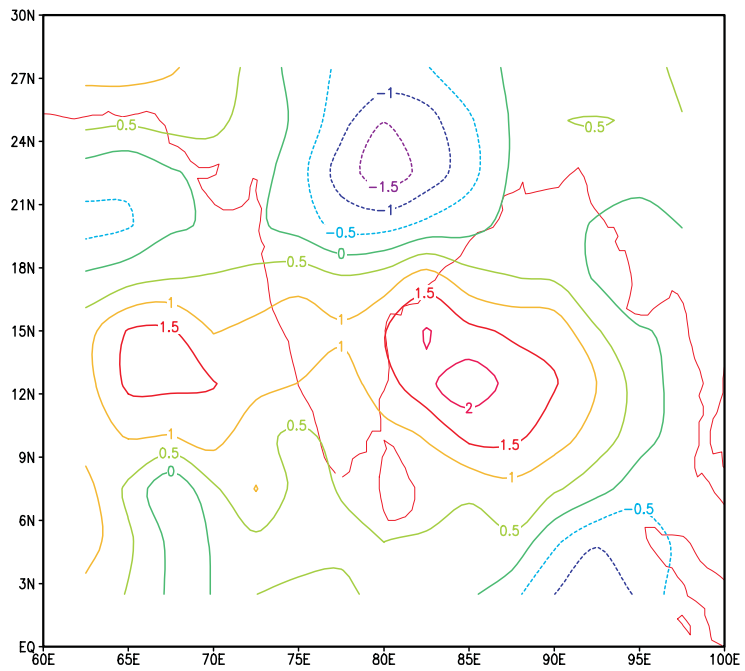

23.08 .00

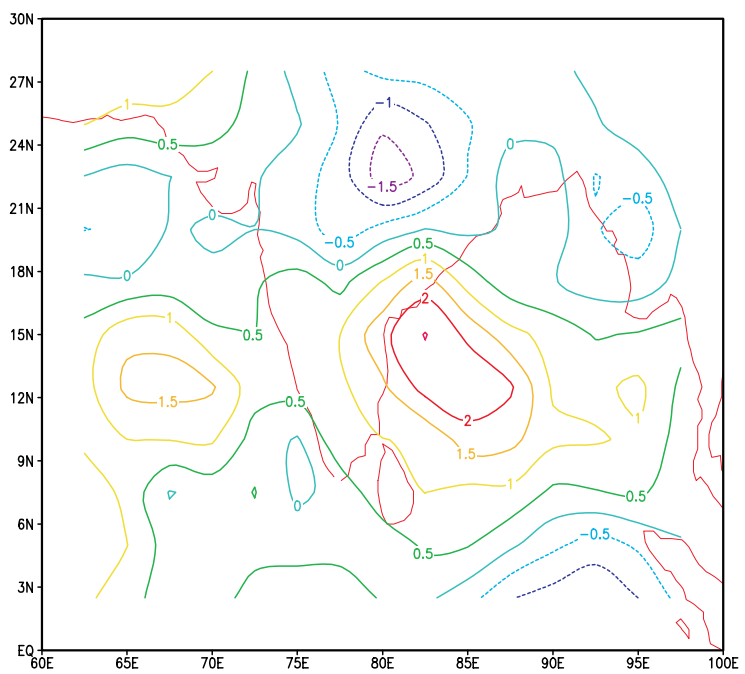

20.08 .00

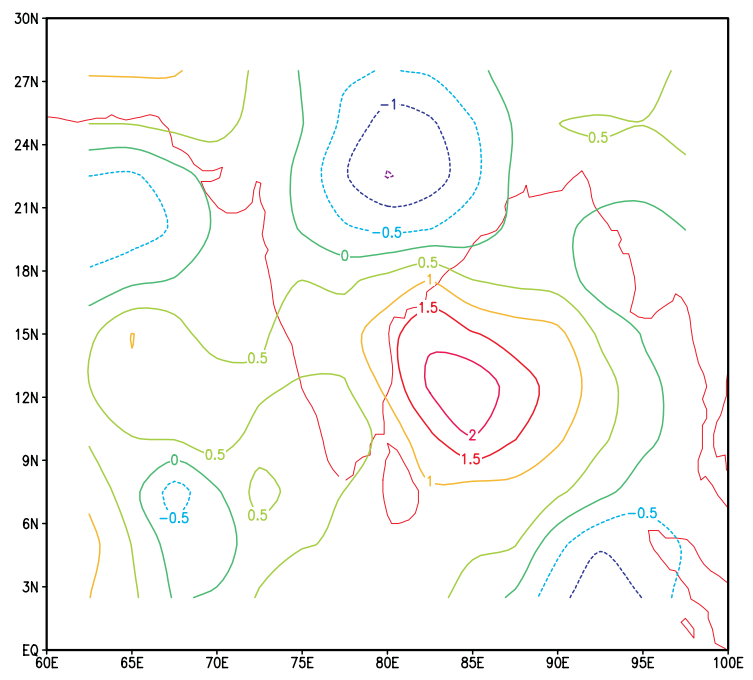

22.08 .00

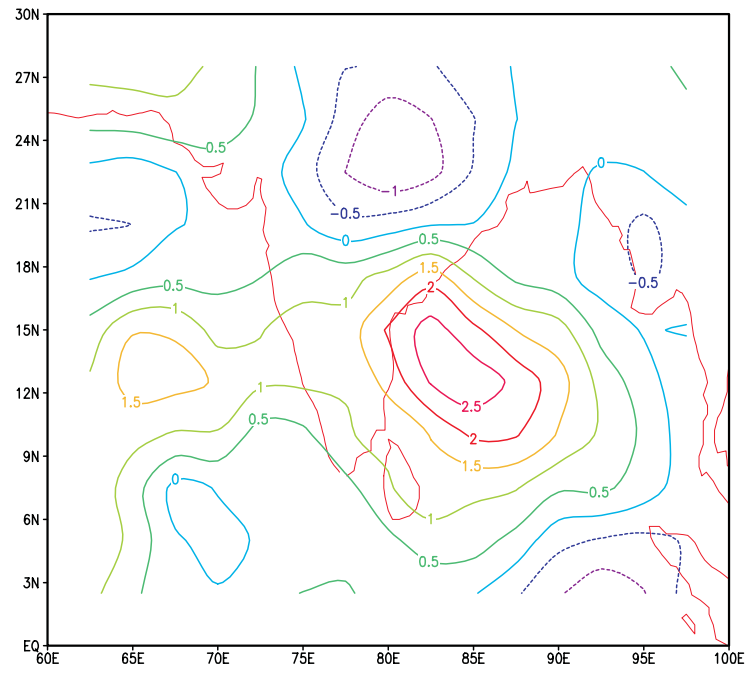

24.08 .00

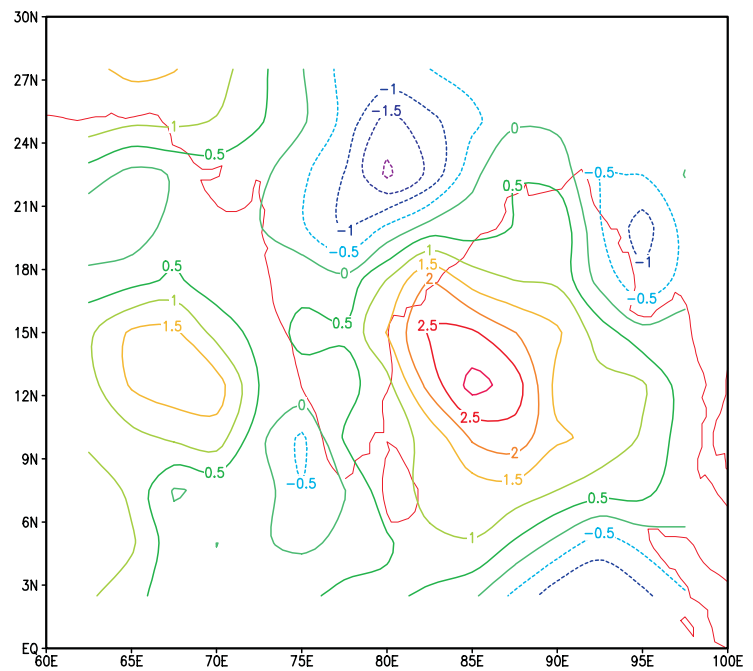

Figure 8. Divergence $\left(10^{-5} / \mathrm{s}\right)$ analysis at $200 \mathrm{hPa}$ for 19 th-24th August 2000 . 
Meteorology and Shri. P Seetaramayya, Head, Forecasting Research Division for providing facilities and showing keen interest in the study. Thanks are extended to Dr. R R Navalgund, Director NRSA, Hyderabad and Dr. Abhijit Sarkar, scientist, SAC, Ahmedabad for their full support. Thanks are also extended to IMD and NRSA for making available the required conventional and satellite data for this study.

\section{References}

Ali M M and Collaborators 2000 Validation of multifrequency scanning microwave radiometer geophysical data products; Pacific Ocean Remote Sensing Conference (PORSEC-2000) 182-191

Bhalme H N 1972 Trends and quasi-bionnial oscillation in the series of cyclonic disturbances over the Indian region; Indian J. Met. Geophys. 23 355-358

Eliot J 1884 Accounts of southwest monsoon storms generated in the Bay of Bengal during 1877-188; Mem. India Met. Dept. 2 217-448

Gohil B S, Mathur A K and Varma A K 2000 Geophysical parameter retrieval over global oceans from IRSP4 MSMR; Pacific Ocean Remote Sensing Conference (PORSEC-2000) 207-211

Kamineni R, Rizvi S R H, Kar S C, Mohanti U C and Paliwal R K 2002 Assimilation of IRS-P4 (MSMR) meteorological data in the NCMRWF global data assimilation system; Proc. Indian Aca. Sci. (Earth Planet. Sci.) 111 351-364

Mahajan P N 2001 Utility of DMSP-SSM/I for integrated water vapour over the Indian seas; Proc. Indian Acad. Sci. (Earth Planet. Sci.) $110225-229$

Mahajan P N 2002a DMSP-SSM/I retrieval of proper surface winds during monsoon depression; Mausam 53 367373

Mahajan P N 2002b Signal of weakening of tropical cyclone through multiple satellite approach; Tropmet 2002 (submitted for publication)

Mooley D A 1973 Some aspects of Indian monsoon depressions and associated rainfall; Mon. Weather Rev. 101 271-280

Pisharoty P R and Asnani G C 1957 Rainfall around monsoon depression over India; Indian J. Met. Geophys. 8 $15-20$

Rao K N and Jayaraman S 1958 A statistical study of frequency of depressions/cyclones in the Bay of Bengal; Indian J. Met. Geophys. 9 233-250

Sarkar R P and Chowdhury A 1988 A diagnostic structure of monsoon depressions; Mausam 39 9-18

Srinivasan V 1953 Variation of cyclonic circulation with height in September 1951 deep depression; Indian J. Met. Geophys. 4 263-264

Sikka D R 1977 Some aspects of life history, structure and movement of monsoon depression; Pure and Appl. Geophys. Basel 115 1501-1529

Varma A K, Gairola R M, Mathur A K, Gohil B S and Agarwal V K 2002 Intercomparison of IRS-P4 MSMR derived geophysical products; Proc. Indian Acad. Sci. $111247-255$ 